\title{
Quantitation of Site-Specific Glycosylation in Manufactured Recombinant Monoclonal Antibody Drugs
}

Nan Yang ${ }^{1,3,4}$, Elisha Goonatilleke ${ }^{2,4}$, Dayoung Park ${ }^{2}$, Ting Song ${ }^{2}$, Guorong Fan ${ }^{1,3}$, Carlito B. Lebrilla $^{2, *}$

${ }^{1}$ School of Pharmacy, Second Military Medical University, Guohe Road, Shanghai, 200433, China

${ }^{2}$ Department of Chemistry, University of California, Davis, One Shields Avenue, Davis, CA 95616, United States

${ }^{3}$ Department of Pharmacy, Shanghai General Hospital, Haining Road, Shanghai, 200080, China

${ }^{4}$ These authors contributed equally to this work

\section{Corresponding Author}

*E-mail: cblebrilla@ucdavis.edu. Phone: +1 530752 6364. Fax: +1 5307528995. 


\section{SUPPORTING INFORMATION}

Figure S1. MRM chromatograms of the transitions with two fragment ions for: (a) glycopeptide 4.4.1.0.0 from $\operatorname{IgG1}$, and (b) glycopeptide 4.4.1.0.0 from $\operatorname{IgG} 2$.

Figure S2. The ratio of IgG subclasses in six rMAb drugs.

Table S1. MRM transitions used to monitor glycopeptides. 


\section{Figure S1.}

(a)

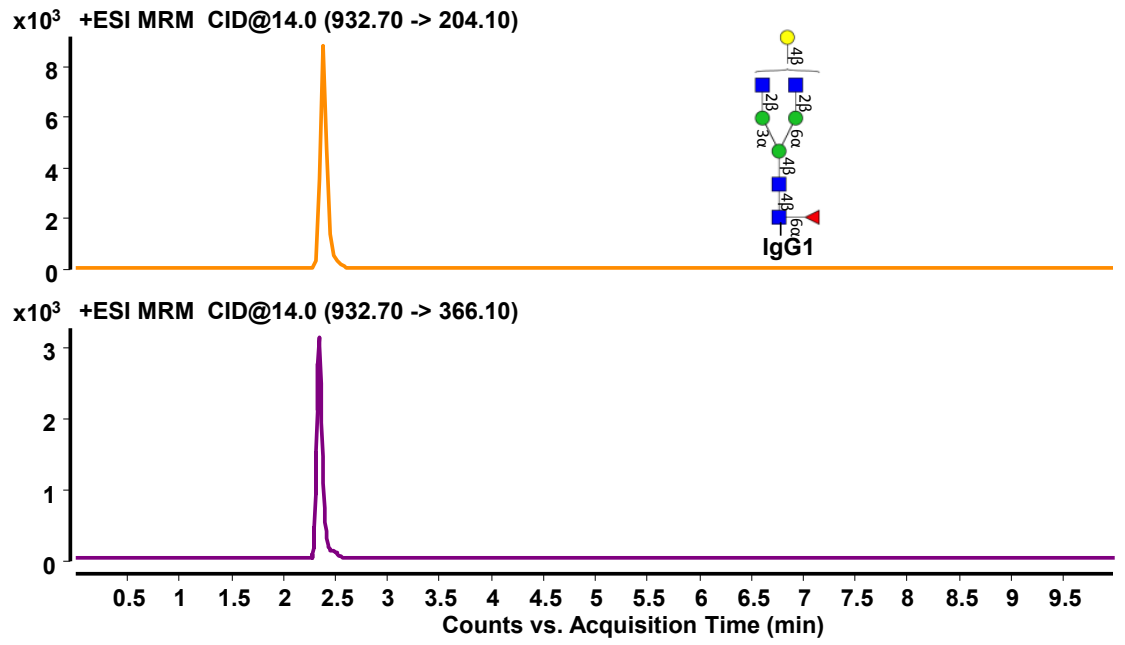

(b)

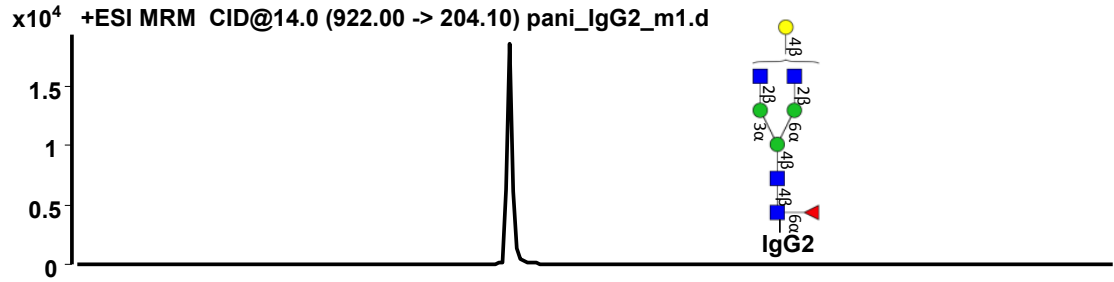

x10 ${ }^{4}$ +ESI MRM CID@14.0 (922.00 -> 366.10) pani_IgG2_m1.d

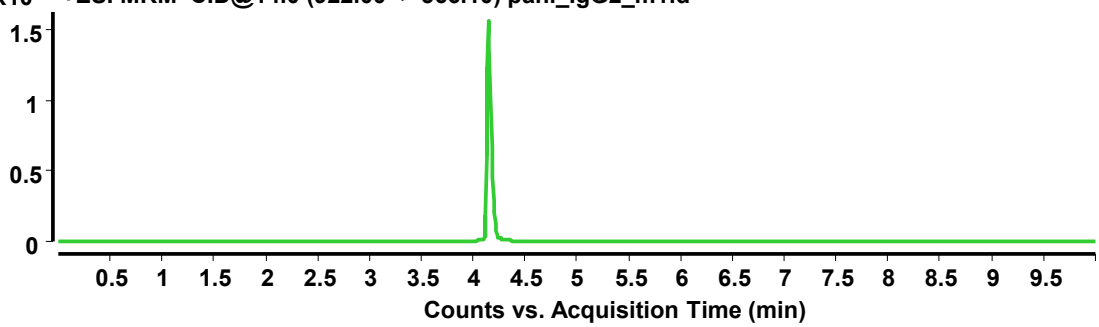


Figure S2.

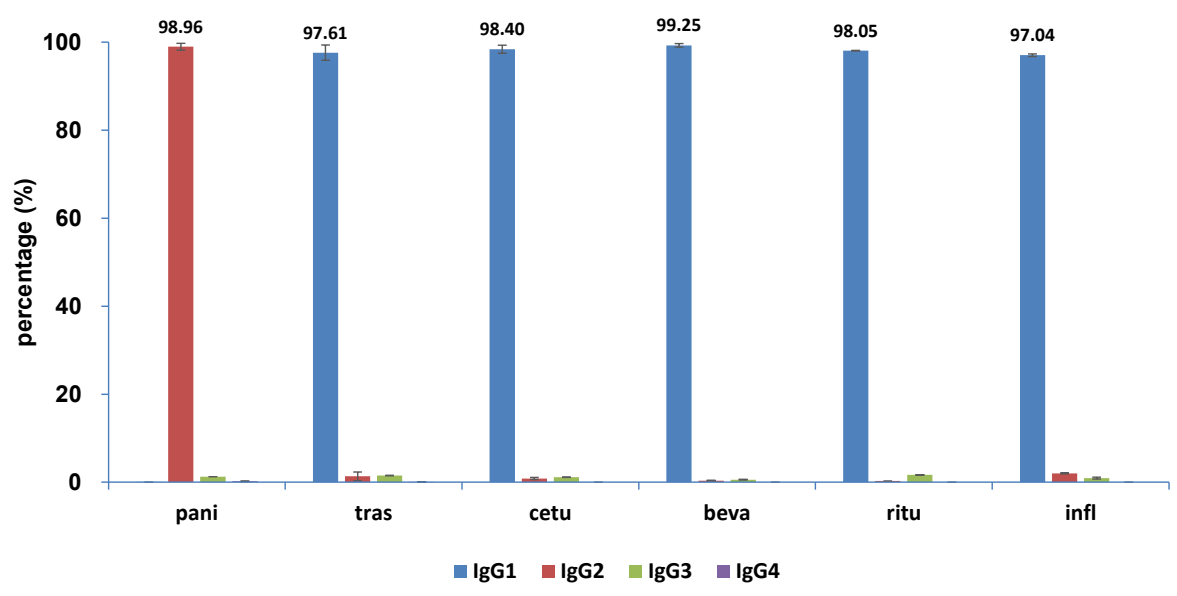


Table S1.

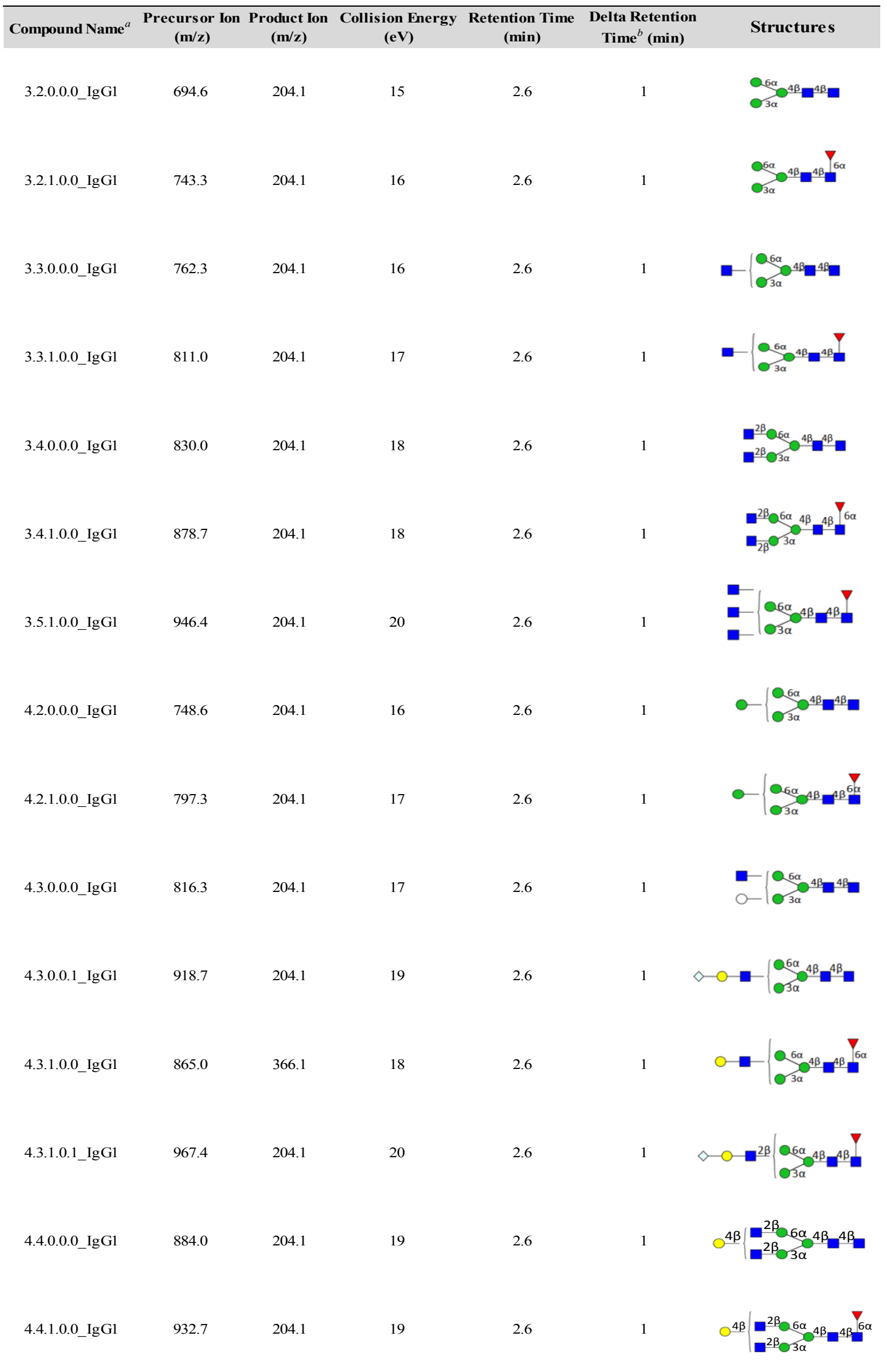




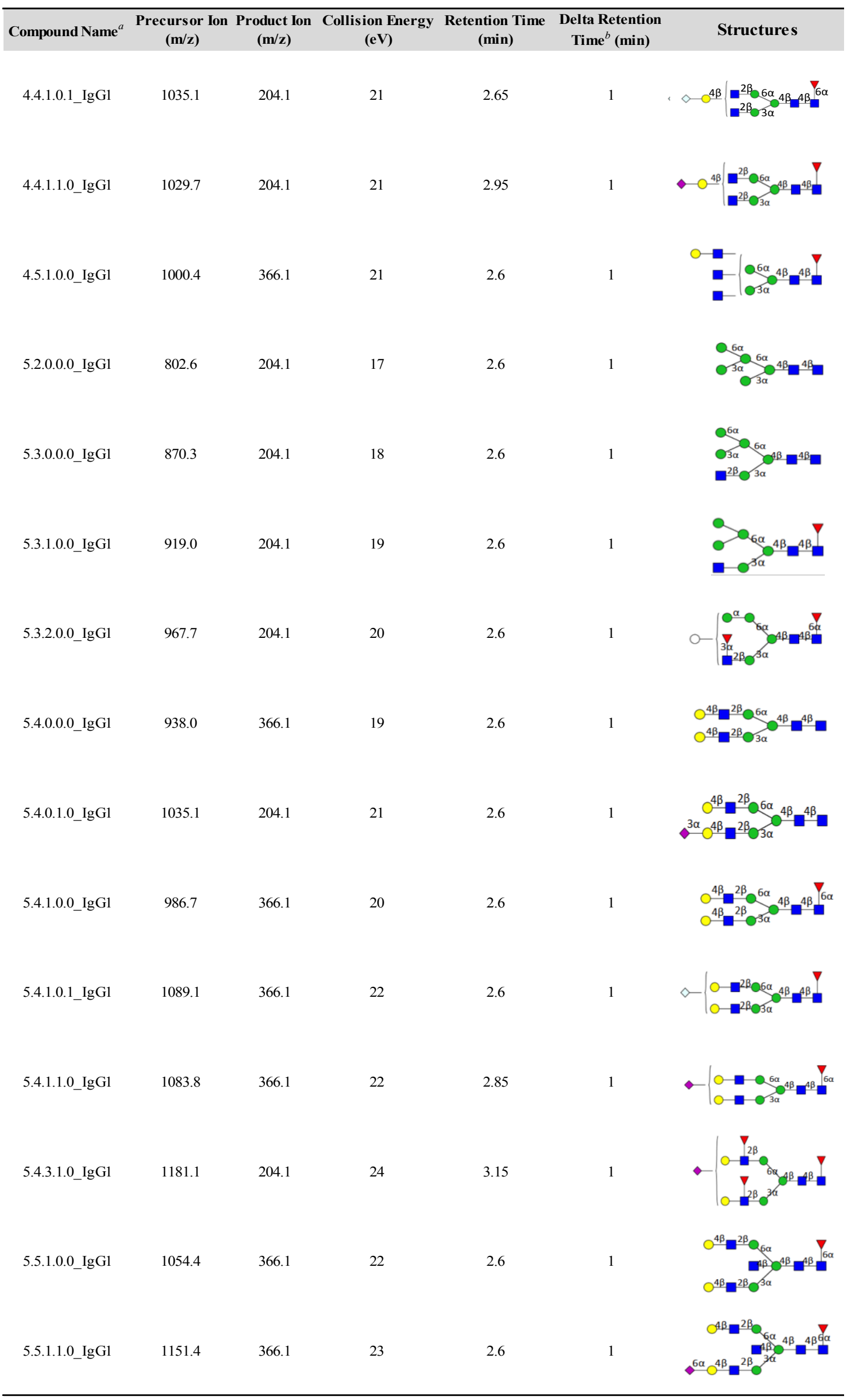




\begin{tabular}{|c|c|c|c|c|c|c|}
\hline Compound Name $^{a}$ & $\begin{array}{c}\text { Precursor Ion } \\
(\mathbf{m} / \mathbf{z})\end{array}$ & $\begin{array}{l}\text { Product Ion } \\
(\mathrm{m} / \mathbf{z})\end{array}$ & $\begin{array}{c}\text { Collision Energy } \\
\text { (eV) }\end{array}$ & $\begin{array}{c}\text { Retention Time } \\
\text { (min) }\end{array}$ & $\begin{array}{c}\text { Delta Retention } \\
\text { Time }^{b} \text { (min) }\end{array}$ & Structures \\
\hline 6.2.0.0.0_IgG1 & 856.7 & 204.1 & 18 & 2.6 & 1 & 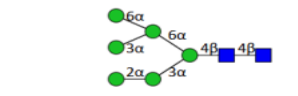 \\
\hline 6.3.0.0.0_IgG1 & 924.4 & 366.1 & 19 & 2.6 & 1 & $\underbrace{-6 \alpha}_{03 \alpha}$ \\
\hline 6.3.0.0.1_IgG1 & 1026.7 & 204.1 & 21 & 2.6 & 1 & 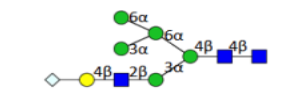 \\
\hline 6.3.1.0.0_IgG1 & 973.0 & 204.1 & 20 & 2.6 & 1 & o- \\
\hline 6.4.0.0.0_IgG1 & 992.1 & 204.1 & 20 & 2.6 & 1 & - \\
\hline 6.4.1.0.0_IgG1 & 1040.7 & 204.1 & 21 & 2.6 & 1 & 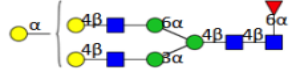 \\
\hline 6.4.2.0.0_IgG1 & 1089.4 & 366.1 & 22 & 2.6 & 1 & $\mathbf{I}^{\mathrm{NO}-}$ \\
\hline 6.4.3.0.0_IgG1 & 1138.1 & 204.1 & 23 & 2.6 & 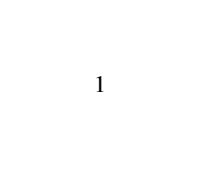 & 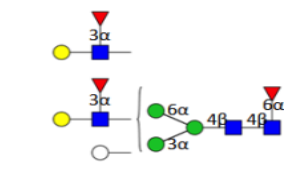 \\
\hline 6.5.0.0.3_IgG1 & 1366.8 & 204.1 & 27 & 2.6 & 1 & 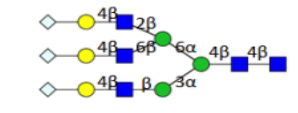 \\
\hline 7.2.0.0.0_IgG1 & 910.7 & 204.1 & 19 & 2.6 & 1 & 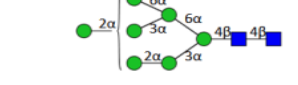 \\
\hline 7.4.1.0.0_IgG1 & 1094.8 & 204.1 & 22 & 2.6 & 1 & 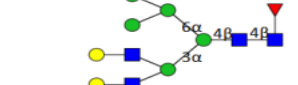 \\
\hline 7.5.1.0.0_IgG1 & 1162.4 & 204.1 & 24 & 2.6 & 1 & 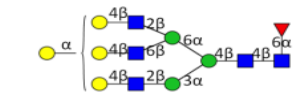 \\
\hline 7.5.1.0.1_IgG1 & 1264.8 & 204.1 & 25 & 2.6 & 1 & 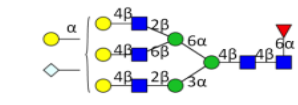 \\
\hline 7.5.2.0.0_IgG1 & 1211.1 & 366.1 & 24 & 2.6 & (2. & 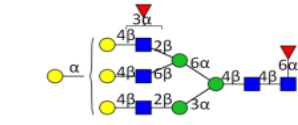 \\
\hline 8.2.0.0.0_IgG1 & 964.7 & 204.1 & 20 & 2.6 & 1 & 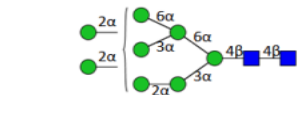 \\
\hline Peptide_IgG1 & 839.41 & 968.48 & 30 & 5.5 & 1 & FNWYVDGVEVHNAK \\
\hline
\end{tabular}




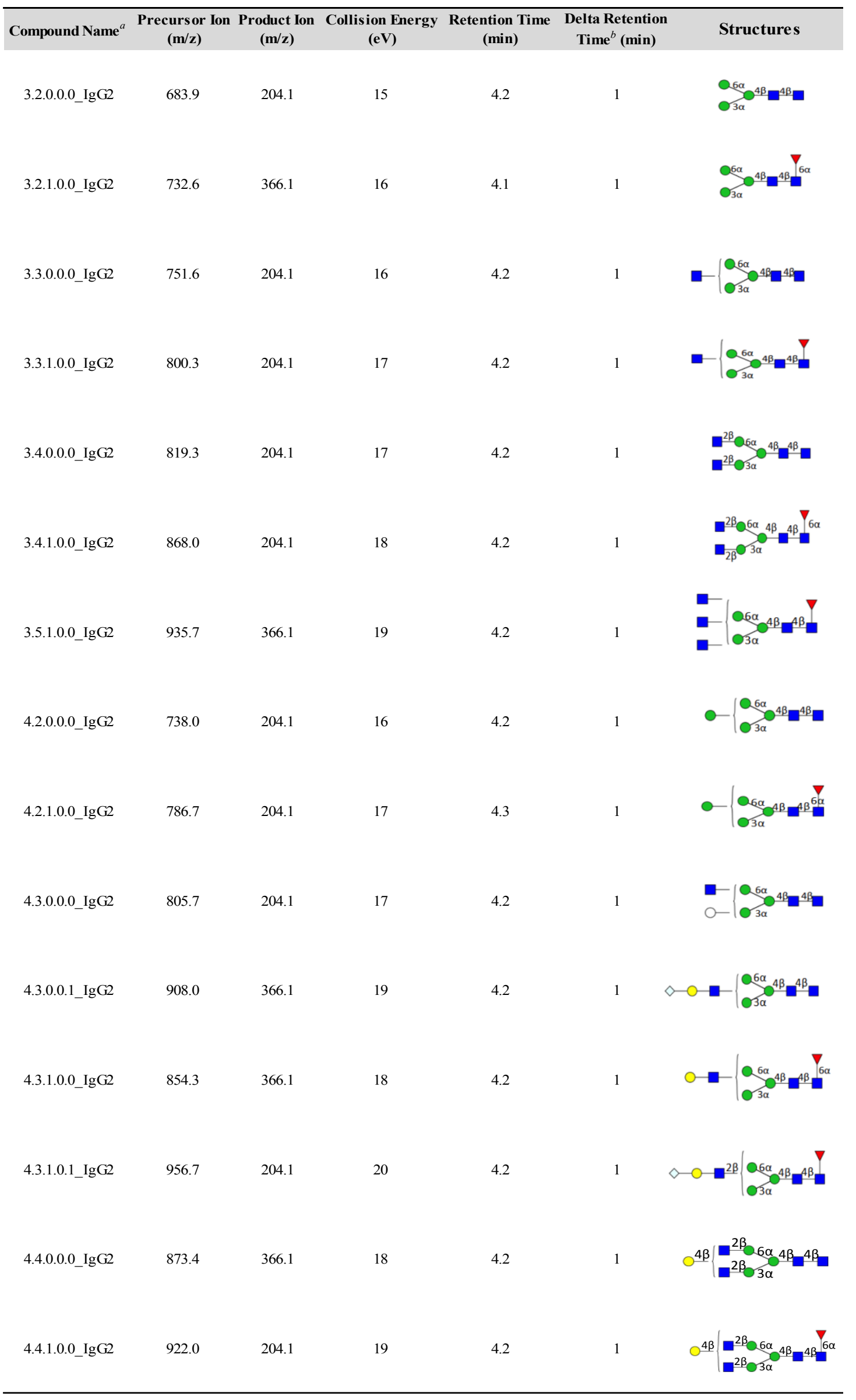




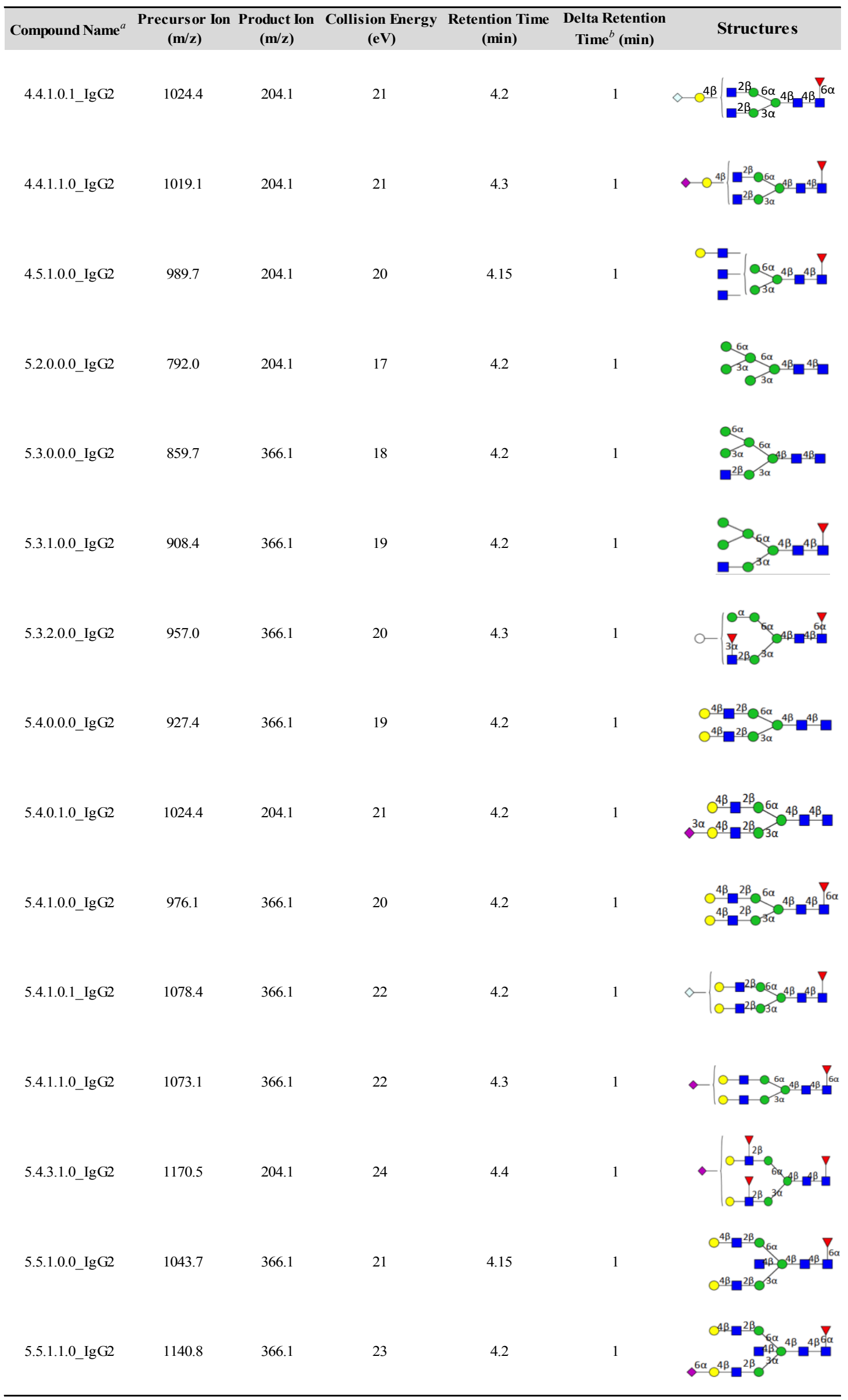




\begin{tabular}{|c|c|c|c|c|c|c|}
\hline Compound Name ${ }^{a}$ & $\begin{array}{c}\text { Precursor Ion } \\
(\mathrm{m} / \mathrm{z})\end{array}$ & $\begin{array}{l}\text { Product Ion } \\
(\mathbf{m} / \mathbf{z})\end{array}$ & $\begin{array}{c}\text { Collision Energy } \\
(\mathrm{eV})\end{array}$ & $\begin{array}{c}\text { Retention Time } \\
\text { (min) }\end{array}$ & $\begin{array}{c}\text { Delta Retention } \\
\text { Time }^{b} \text { (min) }\end{array}$ & Structures \\
\hline 6.2.0.0.0_IgG2 & 846.0 & 204.1 & 18 & 4.2 & 1 & 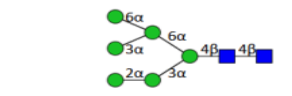 \\
\hline 6.3.0.0.0_IgG2 & 913.7 & 366.1 & 19 & 4.2 & 1 & 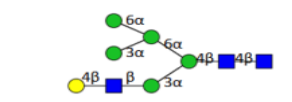 \\
\hline 6.3.0.0.1_IgG2 & 1016.1 & 204.1 & 21 & 4.3 & 1 & $\diamond 0^{4}$ \\
\hline 6.3.1.0.0_IgG2 & 962.4 & 366.1 & 20 & 4.15 & 1 & - \\
\hline 6.4.0.0.0_IgG2 & 981.4 & 366.1 & 20 & 4.15 & 1 & 0 \\
\hline 6.4.1.0.0_IgG2 & 1030.1 & 366.1 & 21 & 4.15 & 1 & 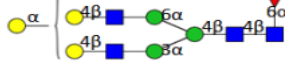 \\
\hline 6.4.2.0.0_IgG2 & 1078.8 & 204.1 & 22 & 4.2 & 1 & $\stackrel{\mathbf{v}^{3 \times}}{\mathrm{a}^{\circ}-}$ \\
\hline 6.4.3.0.0_IgG2 & 1127.4 & 204.1 & 23 & 4.2 & 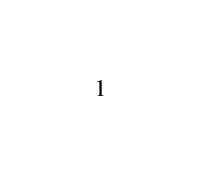 & 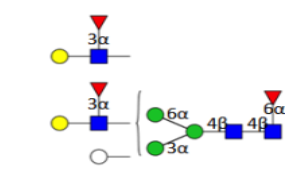 \\
\hline 6.5.0.0.3_IgG2 & 1356.2 & 204.1 & 27 & 4.2 & 1 & 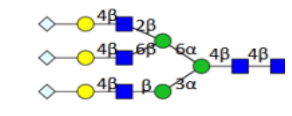 \\
\hline 7.2.0.0.0_IgG2 & 900.0 & 204.1 & 19 & 4.2 & 1 & 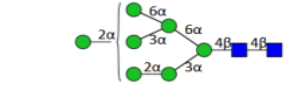 \\
\hline 7.4.1.0.0_IgG2 & 1084.1 & 204.1 & 22 & 4.3 & 1 & 0 \\
\hline 7.5.1.0.0_IgG2 & 1151.8 & 204.1 & 23 & 4.2 & 1 & 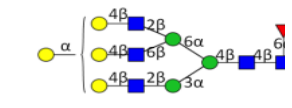 \\
\hline 7.5.1.0.1_IgG2 & 1254.1 & 204.1 & 25 & 4.2 & 1 & 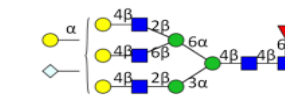 \\
\hline 7.5.2.0.0_IgG2 & 1200.5 & 204.1 & 24 & 4.2 & 1 & 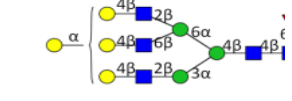 \\
\hline 8.2.0.0.0_IgG2 & 954.0 & 366.1 & 20 & 4.2 & 1 & $\left.\odot^{2 \alpha}\right|_{0,3 \alpha} ^{6 \alpha} \int_{3 \alpha}^{6 \alpha} \int_{3 \beta}^{4 \beta}$ \\
\hline $\mathrm{IgG} 2$ & 970.14 & 1100.62 & 28 & 6.2 & 1 & $\begin{array}{l}\text { CCVECPPCPAPPVAGP } \\
\text { SVFLFPPKPK }\end{array}$ \\
\hline
\end{tabular}




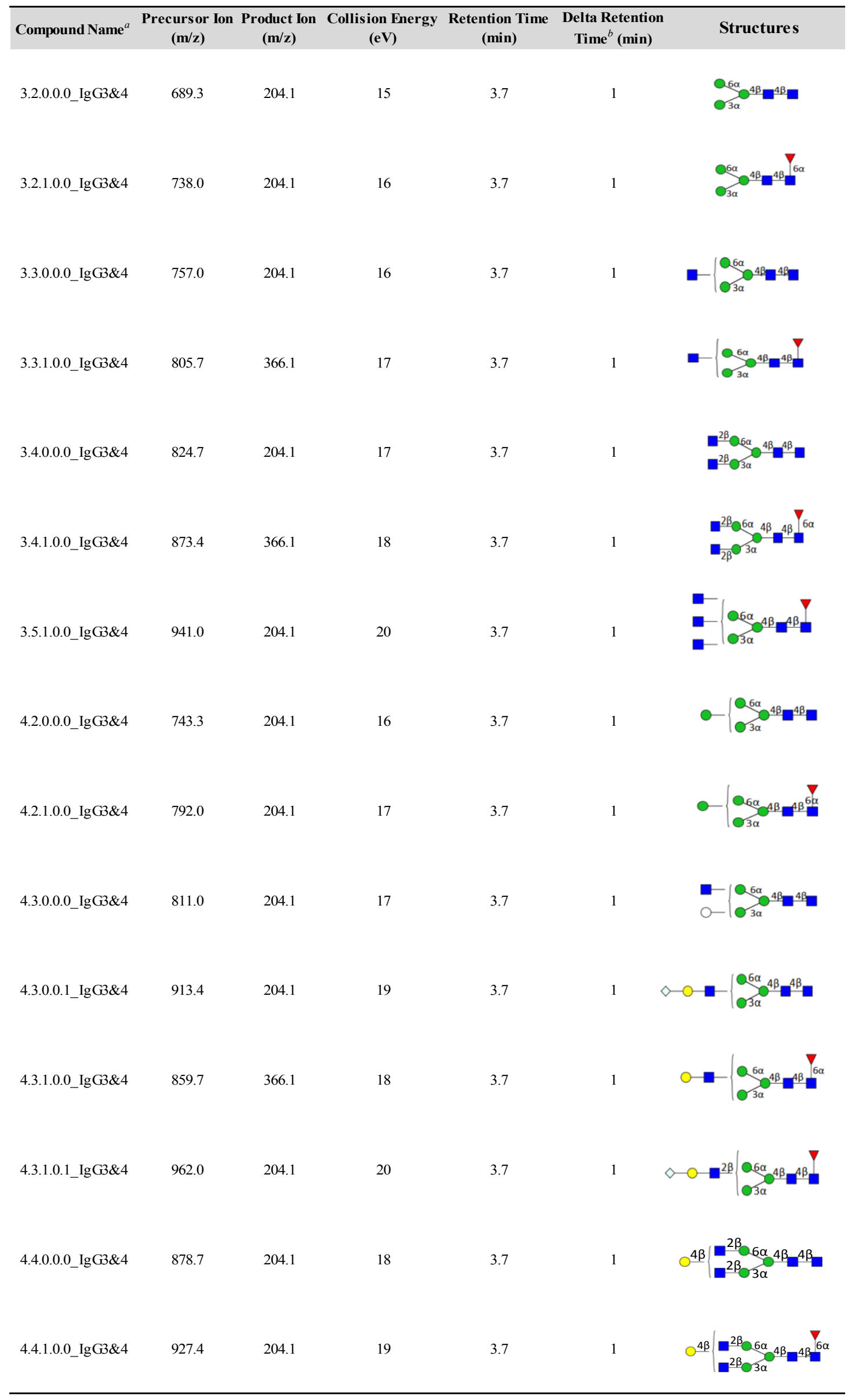




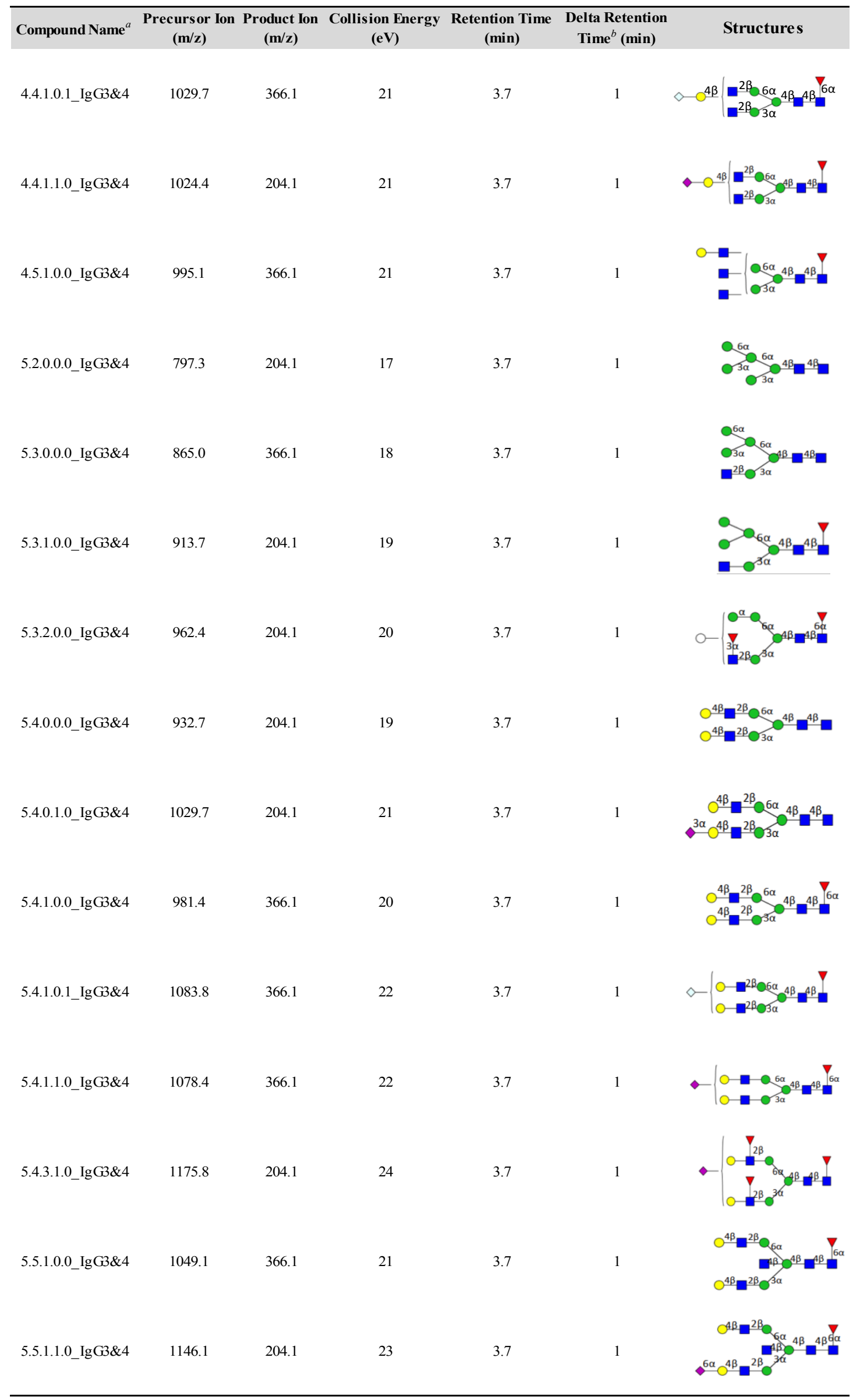




\begin{tabular}{|c|c|c|c|c|c|c|}
\hline Compound Name $^{a}$ & $\begin{array}{c}\text { Precursor Ion } \\
(\mathbf{m} / \mathbf{z})\end{array}$ & $\begin{array}{l}\text { Product Ion } \\
(\mathbf{m} / \mathbf{z})\end{array}$ & $\begin{array}{c}\text { Collision Energy } \\
(\mathrm{eV})\end{array}$ & $\begin{array}{c}\text { Retention Time } \\
\text { (min) }\end{array}$ & $\begin{array}{l}\text { Delta Retention } \\
\text { Time }^{b} \text { (min) }\end{array}$ & Structures \\
\hline 6.2.0.0.0_IgG3\&4 & 851.3 & 204.1 & 18 & 3.7 & 1 & \\
\hline 6.3.0.0.0_IgG3\&4 & 919.0 & 366.1 & 19 & 3.7 & 1 & 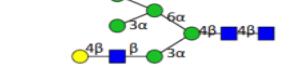 \\
\hline 6.3.0.0.1_IgG3\&4 & 1021.4 & 366.1 & 21 & 3.7 & 1 & 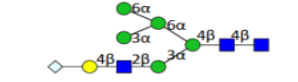 \\
\hline 6.3.1.0.0_IgG3\&4 & 967.7 & 204.1 & 20 & 3.7 & 1 & - \\
\hline 6.4.0.0.0_IgG3\&4 & 986.7 & 366.1 & 20 & 3.7 & 1 & $\circ$ \\
\hline 6.4.1.0.0_IgG3\&4 & 1035.4 & 204.1 & 21 & 3.7 & 1 & 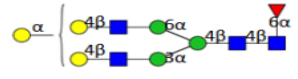 \\
\hline 6.4.2.0.0_IgG3\&4 & 1084.1 & 366.1 & 22 & 3.7 & 1 & $\mathbf{I}^{2 \times-}$ \\
\hline 6.4.3.0.0_IgG3\&4 & 1132.8 & 204.1 & 23 & 3.7 & 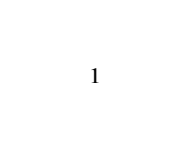 & 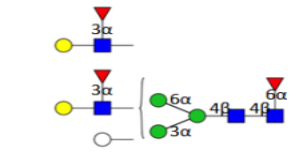 \\
\hline 6.5.0.0.3_IgG3\&4 & 1361.5 & 204.1 & 27 & 3.7 & 1 & 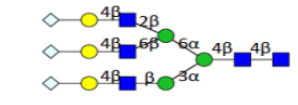 \\
\hline 7.2.0.0.0_IgG3\&4 & 905.4 & 366.1 & 19 & 3.7 & 1 & 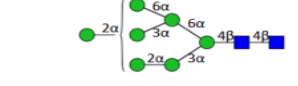 \\
\hline 7.4.1.0.0_IgG3\&4 & 1089.4 & 204.1 & 22 & 3.7 & 1 & 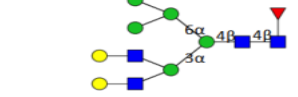 \\
\hline 7.5.1.0.0_IgG3\&4 & 1157.1 & 366.1 & 23 & 3.7 & 1 & 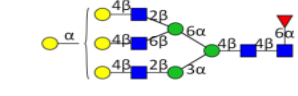 \\
\hline 7.5.1.0.1_IgG3\&4 & 1259.5 & 366.1 & 25 & 3.7 & 1 & 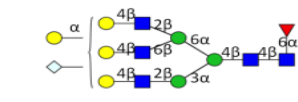 \\
\hline 7.5.2.0.0_IgG3\&4 & 1205.8 & 204.1 & 24 & 3.7 & 1 & 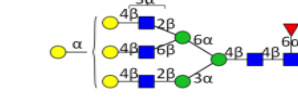 \\
\hline 8.2.0.0.0_IgG3\&4 & 959.4 & 204.1 & 20 & 3.7 & 1 & 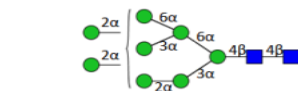 \\
\hline \multirow[t]{2}{*}{ IgG1234 } & 581.3 & 342.18 & 14 & 5.4 & 1 & DTLMISR \\
\hline & & 243.1 & 14 & 5.4 & 1 & DTLMISR \\
\hline $\operatorname{IgG} 3$ & 472.9 & 697.36 & 6 & 4.9 & 1 & WYVDGVEVHNAK \\
\hline IgG4 & 634.98 & 425.214 & 9 & 6.4 & 1 & TTPPVLDSDGSFFLYSR \\
\hline
\end{tabular}

